www.jmscr.igmpublication.org

Index Copernicus Value: 79.54

ISSN (e)-2347-176x ISSN (p) 2455-0450

crossrefDOI: https://dx.doi.org/10.18535/jmscr/v7i3.71

\title{
Immediate Effect of Myofascial Release on pain and Shoulder Range of Motion in Periarthritis Shoulder
}

\author{
Authors \\ Paras Karia ${ }^{1}$, Dr Bindu Sarfare $(\text { PT })^{2}$, Dr Snehal Ghodey $(\text { PT })^{3}$ \\ ${ }^{1}$ Intern at MAEERs Physiotherapy College, Talegaon Dabhade, India \\ ${ }^{2}$ Associate Professor at MAEERs Physiotherapy College, Talegaon Dabhade, India \\ ${ }^{3}$ Principal at MAEERs Physiotherapy College, Talegaon Dabhade India
}

\begin{abstract}
Aim: To study immediate effect of Myofascial release in pain and shoulder ROM in Stage 1 Periarthritis shoulder.

Subjects and Method: Forty individuals with painful and restricted glenohumeral ROM were selected. Subjects who were willing to participate in study and fulfil inclusion and exclusion criteria were included and randomly classified into experimental group $(n=20)$, which received therapy consisting of Interferential therapy (IFT) (20 minutes), Hot pack (10 minutes) and Myofascial release to Upper Trapezius, Infraspinatus, Teres Major and Deltoid for an approximate duration of 15 minutes, while that of control group $(n=20)$ received treatment without MFR. Pain levels using NPRS and shoulder ROM using Universal Goniometer were assessed pre and post - interventions by a single blinded assessor.

Results: Both groups had extremely significant improvement in outcome measures. However, Experimental group showed better results than control group.

Conclusion: The combination of myofascial release along with conventional therapy was effective in alleviating pain and improving glenohumeral ROM immediately after a single intervention session

Keywords: Myofascial Release, Periarthritis shoulder.
\end{abstract}

\section{Introduction}

Duplay (1872) depicted Periarthritis (PA) shoulder and addressed it 'Periarthrite scapulohumerale'. ${ }^{[1]}$ Codman (1934) defined Frozen shoulder (FS) showing stiffness, night pain with difficulty in performing overhead activities. $^{\text {[2] }}$

Prevalence in individuals past 40 years age with greatest incidence found with 50 and 60 years in women. It affects almost $26 \%$ of adult population. [3]
Reeves has classified three stages of disease: first stage has pain and progressive limitation of external - internal rotation, abduction and flexion. Pathologically structures reveal hypertrophic, hypervascular synovitis, rare inflammatory cell infiltrates within a normal underlying capsule. Second stage (freezing), presents with chronic pain on active -passive ROM. Forward flexion, abduction, internal and external rotation are significantly reduced Pathologic changes reveal hypertrophic, hypervascular synovitis, perivascular and subsynovial scar, fibroplasia and 
scar formation in underlying capsule. Final or thawing phase resulting from capsular remodeling leading to slow, steady recovery in ROM. ${ }^{[4]}$

Various treatment options applied in management of shoulder disorders, few proved effective in RCTs. ${ }^{[5]}$

NSAIDs, local anaesthetic or corticosteroid injections for glenohumeral joint, calcitonin, antidepressants, distension arthrography, closed manipulation, physical therapy modalities with stretching exercises are common non-surgical approaches for PA shoulder. Self-limiting nature of FS in long term, complicates efficacy with treatment methods. Hence, reasonable to have a treatment program aimed at a rapid recovery rate with minimum visits to hospital after which follow- up period of home exercise program.

Myofascial therapy, defined as "the facilitation of mechanical, neural and psychophysiological adaptive potential as interfaced via the system". ${ }^{[6]}$ Recent studies suggested in FS Active Myofascial Trigger Points (MTrPs) most prevalent in Infraspinatus $(77 \%)$ and Upper Trapezius muscle (58\%) whereas latent MTrPs in Teres Major (49\%) and Anterior Deltoid muscle (38\%) concluding one session of release and heat improved muscle activation increasing shoulder ROM. ${ }^{[7]}$

In numerous situations fascia restricts movement with no pain. Myofascial technique releases fascia deeply.

The purpose is to see alleviation of pain scores with increased ROM immediately post intervention.

\section{Subjects and Method}

40 patients between the ages of 40-60 years, with $1^{\text {st }}$ stage of Periarthritis shoulder, participated in the study. Subjects for the study were selected based on the following inclusion criteria, having painful and stiff shoulder, limited ROM of shoulder joint, both genders and First stage of Periarthritis shoulder. Exclusion criteria consists of history of surgery on the shoulder, rheumatoid arthritis, painful stiff shoulder after severe trauma, fracture of the shoulder complex, rotator cuff rupture, tendon calcification, second and third stage of Periarthritis shoulder and Osteoarthrosis. Institutional Ethical committee was taken. Subjects were selected based on inclusion and exclusion criteria by purposive sampling. An informed consent was taken from each subject.40 patients with inclusion criteria whose informed consent will be taken will participate in the study and will be randomly distributed in 2 groups. Group A (Experimental group)- Myofascial release + conventional therapy 20 patients. Group B (Control group) - conventional therapy 20 patientsDuration- both the groups will be treated, and immediate effect will be assessed for Pain levels using Numerical Pain Rating Score (NPRS) and Shoulder ROM will be measured using Universal Goniometer by a Single Blinded Assessor with the patient in supine-lying on a treatment table with a pillow under the knees. Stabilization of the scapula was achieved by depressing the shoulder girdle. The subjects in the experimental group received a single session of Interferential therapy (IFT- 4 Pole Vector around the shoulder) for 20 minutes, hot pack (42-44 degree Celsius) for 10 minutes and then Myofascial release to Deltoid, Upper Trapezius, Teres Major and Infraspinatus muscles for an approximate period of 15 minutes. After the hot pack the whole area is revisited for fascial restrictions. Fascia is the membrane that surrounds entire muscles, muscle fibers, fibrils and smaller structures down to cellular level. There are numerous situations where fascia restricts movement without pain, in some cases of PA shoulder. MFR uses specific techniques to release fascia, deep down into the joint. Land on the surface of the body with appropriate 'tool' (fingers, ulnar border of hand, finger or thumb pad). Sink into the soft tissue. Contact the first barrier/restricted layer. Put in a line of tension. Engage the fascia by taking up the slack in the tissue. Finally, move or drag the fascia across the surface while staying in touch with the underlying layers. Exit gracefully. Apply for 5 seconds on 
and 2-3 seconds off until the client reports a reduction in local pain until 2 minutes for each muscle. The subjects in the control group received only Interferential therapy and Hot pack.

\section{Results}

Descriptive statistics was done in the form of mean and standard deviation. Interferential statistics evaluated changes in NPRS and Shoulder ROM using Mann Whitney test between the groups and Wilcoxon matched pairs test was used to measure changes within group, analysis was done using InStat (Version 3.05, created
September 2000). Significance was accepted with $\mathrm{p}<0.05$.

Gender distribution: The gender distribution among 40 subjects who participated in Group A have 4 males (13.33\%) and 16 females (40\%) and Group B have 9 males $(22.5 \%)$ and 11 females $(27.5 \%)$.

Age distribution: Age distribution among 40 subjects in both Group A and Group B is 50.2.

There is significant difference in NPRS between groups.

There is significant difference between groups in shoulder range of motion as $p$ values for all movements is significant.

Tables 1: Pre and Post means of NPRS (Wilcoxon matched pairs test)

\begin{tabular}{|l|l|l|l|l|}
\hline NPRS & Pre-Mean (SD) & Post- Mean (SD) & p Value & Significance \\
\hline EXPERIMENTAL GROUP & $6.45 \pm 0.94$ & $2.55 \pm 0.88$ & 0.0001 & Extremely significant \\
\hline CONTROL GROUP & $6.25 \pm 0.91$ & $3.5 \pm 0.68$ & 0.0001 & Extremely significant \\
\hline
\end{tabular}

Tables 2: Comparison of mean difference of NPRS (Mann Whitney test)

\begin{tabular}{|l|c|c|c|c|c|}
\hline $\begin{array}{l}\text { OUTCOME } \\
\text { MEASURE }\end{array}$ & $\begin{array}{c}\text { EXPERIMENTAL } \\
\text { MEAN (SD) }\end{array}$ & $\begin{array}{c}\text { CONTROL } \\
\text { MEAN(SD) }\end{array}$ & p Value & Significance & $\begin{array}{c}\text { Mann Whitney } \\
\text { U - Statistic }\end{array}$ \\
\hline NPRS & $3.9 \pm 0.91$ & $2.75 \pm 0.78$ & $<0.0001$ & $\begin{array}{c}\text { Extremely } \\
\text { significant }\end{array}$ & 67.5 \\
\hline
\end{tabular}

Tables 3: Comparison of ROM pre and post treatment (Wilcoxon matched pairs test)

\begin{tabular}{|l|c|c|c|c|c|c|}
\hline Range of motion & \multicolumn{2}{|c|}{ Experimental Group } & \multirow{2}{*}{$\mathrm{p}$ Value } & \multicolumn{2}{|c|}{ Control Group } & \multirow{2}{*}{$\mathrm{p}$ Value } \\
\cline { 5 - 6 } & Pre-mean & Post- mean & & Pre-mean & Post- mean & \\
\hline Flexion & 130.5 & 143.2 & 0.0001 & 144.6 & 149.4 & 0.0001 \\
\hline Extension & 40.25 & 47.2 & 0.0001 & 43.1 & 46.3 & 0.0001 \\
\hline Abduction & 100.4 & 113.5 & 0.0001 & 132.3 & 137.75 & 0.0001 \\
\hline Int rotation & 51.0 & 58.5 & 0.0001 & 62.3 & 66.45 & 0.0001 \\
\hline Ext rotation & 43.55 & 51.45 & 0.0001 & 52.45 & 56.60 & 0.0001 \\
\hline
\end{tabular}

Tables 4: Comparison of ROM between groups using Mean Difference and Standard Deviation (Mann Whitney test)

\begin{tabular}{|l|c|c|c|c|c|}
\hline RANGES & $\begin{array}{c}\text { EXPERIMENTAL } \\
\text { MEAN (SD) }\end{array}$ & $\begin{array}{c}\text { CONTROL } \\
\text { MEAN(SD) }\end{array}$ & $\mathrm{p}$ Value & Significance & $\begin{array}{c}\text { Mann Whitney U } \\
\text { - Statistic }\end{array}$ \\
\hline FLEXION & $12.7 \pm 3.64$ & $4.8 \pm 2.37$ & $<0.0001$ & $\begin{array}{l}\text { Extremely } \\
\text { significant }\end{array}$ & 11.0 \\
\hline EXTENSION & $6.95 \pm 3.9$ & $3.2 \pm 1.39$ & $<0.0001$ & $\begin{array}{l}\text { Extremely } \\
\text { significant }\end{array}$ & 52.5 \\
\hline ABDUCTION & $12.1 \pm 6.56$ & $5.45 \pm 1.84$ & $<0.0001$ & $\begin{array}{l}\text { Extremely } \\
\text { significant }\end{array}$ & 63.5 \\
\hline INT ROT. & $7.0 \pm 3.19$ & $4.15 \pm 1.72$ & 0.0004 & $\begin{array}{l}\text { Extremely } \\
\text { significant }\end{array}$ & 85.5 \\
\hline EXT ROT. & $7.9 \pm 2.63$ & $4.15 \pm 1.98$ & $<0.0001$ & $\begin{array}{l}\text { Extremely } \\
\text { significant }\end{array}$ & 52.5 \\
\hline
\end{tabular}


Discussion and Conclusion

Periarthritis (PA) shoulder is a chronic inflammatory disorder which is portrayed by development of dense adhesions, capsular thickening and capsular restrictions. It results in loss of active and passive mobility of shoulder joint. Its onset is insidious and usually seen between 40-60 years.

The study undertaken is to assess immediate and added effect of Myofascial release along with Interferential therapy and Hot pack in patients of PA shoulder.

For the purpose of study 40 individuals of stage 1 PA shoulder with pain and restricted ROM were included in the study and randomly divided into 2 groups, control and experimental group. Out of which 20 subjects under Control group were given conventional treatment consisting of Interferential therapy (20 minutes) and Hot pack (10 minutes) and the other 20 subjects under Experimental group received Myofascial release along with conventional therapy. Each subject received treatment of single session and pre-treatment and post-treatment evaluation was done by a single blinded assessor. In this study NPRS and Shoulder ROM were the outcome measures to evaluate the effect of treatment.

The study revealed that both groups obtained successful outcomes, as measured by significant reduction NPRS and increase in shoulder ROM immediately post-treatment.

Subjects in Experimental group showed more decrease in value of NPRS and more increase in shoulder ROM as compared to control group. These results suggest that clinical interventions consisting of myofascial release as a form of manual therapy along with IFT and Hot pack was more effective for reducing pain and improving shoulder ROM immediately in patients of stage 1 PA shoulder.

This improvement may possibly be attributed to the fact that when myofascial release is used, local chemistry changes due to blanching of nodules followed by hyperaemia. This flushes out trapped metabolic waste products in the surrounding tissue and blood stream, which eliminates the fascia's excessive pressure on the pain sensitive structure. Thus, reducing pain.

MFR may help in increasing shoulder ROM by reducing spasm and tightness which is accompanied by breaking the limitation of muscle or connective tissue around the joints, stimulating the mechanoreceptors, increasing blood flow and neuron conductance, desensitizes the nerve endings and reduced muscle tone or from reflex relaxation of tissues transmitted by greater fascial system.

Application of local heat and the manual muscle release treatment might improve the circulation and modulate the local chemical circulation. This mechanical stimulation (heat and pressure) of this intervention might reduce the pain sensation by providing pre-synaptic inhibition at the dorsal horn of the spinal cord. The improvement in pain might help ease muscle spasms and thus result in the increase in shoulder mobility.

Thus, Myofascial release has an immediate and added effect over conventional therapy in the treatment of stage 1 Periarthritis shoulder. The method is non - invasive, effective.

Thus, Myofascial release can be included in the standardized treatment program for Periarthritis of shoulder.

\section{Acknowledgements}

The authors would like to thank the support of the Guide and Staff of the MAEERs Physiotherapy College, Talegaon Dabhade and also like to thank patients for their willingness to participate in the study.

\section{References}

1. Duplay ES. De la periarthrite scapulohumerale et des raideurs de l'epaule qui en son la consequence Arch Gen Med. 1872;20,513-542.

2. Codman EA. The shoulder. Boston, Massachusetts: Thomas Todd Company; 1934. 
3. Yi - Fen Shih, Pei-Wen Lias and ChunShou Lee. The immediate effect of muscle release intervention on muscle activity and shoulder kinematics in patients with frozen shoulder: a cross-sectional, exploratory study.

4. Reeves B. The natural history of the Frozen shoulder syndrome. Scand J. Rheumatol 1975; 4:193-6.

5. Martin J. Kelly (DPT), Michael A. Shaffer (MSPT) et al J Orthop sports Phys Ther 2013;43(5):A1-A31.

doi:10.2519/jospt.2013.0302 Adhesive Capsulitis: Clinical Practice guidelines by APTA.

6. Carol J. Manhein Slack Incorpoated (2008) The Myofascial Release Manual Fourth edition, Introduction to myofascial release.

7. Carle Bron, Jan Dommerholt, B. Stevenage, M. Sensing and Rob AB Ostendorp : High prevalence of shoulder girdle muscles with myofascial trigger points in patients with shoulder pain. Bron et al BMC Musculoskeletal Disorders (2011), 12:139.

8. Gopal N., Walid Kamal M.A., Additional effect of Trigger point therapy and myofascial release on second stage frozen shoulder among industrial workers. Sanamed Aug 2017.

9. Olivia Flannery, Hannan M. , James C. , Adhesive shoulder capsulitis: does thhe timing of manipulation influence outcome ? Acta Orthop Belg, 2007, 73, 21-25.

10. Carolyn Kisner, Lynn Allen Colby, Therapeutic exs, foundation and technique $6^{\text {th }}$ edition, $2012 \mathrm{ch} \mathrm{17,pg.} \mathrm{546-547.}$

11. G.C.R Hand, N. A. Athanasou, T. Matthews, Henry Smith and A. J. Carr: The pathology of frozen shoulder, Journal of bone and joint surgery - British volume, vol 89-B, 2007 issue 7.928-932.

12. Lippincott Williams and Wilkins. The Classic: loss of scapulohumeral motion (frozen shoulder). A.F. DePalma MD. Ann Surg 1952, 135:193-204.

13. Fusum Guler -Uysal, Ekran Kozannoglu: Adhesive Capsulitis: Comparison of early response to two methods of rehabilitation in adhesive capsulitis, Swiss Med wkly 2004; 134; 353-358.

14. Gordon CM, Andrasik F, Schleip R, Birbaumer N, Rea M. Myofascial Trigger Point release for treating chronic shoulder pain : a novel approach. J. Bodyw Mov Ther 2016; 20: 614-22.

15. Bialosky JE, Bishop MD, Price DD, Robinson ME, George SZ. The mechanisms of manual therapy in the treatment of musculoskeletal pain: a comprehensive model. Man Ther 2009; 14: 531-8.

16. Godges J., Mac Rae H, Longdon C, Tinberg C, MacRae P., The effects of two stretching procedures on hip ROM and gait economy. J. orthop sports Phys Ther. 1989; 10: 350-357.

17. Carle Bron, Michael Sensing, JO LM Franssen and Rob AB Oostendorp : Treatment of myofascial trigger points in shoulder disorders by physical therapy: A randomized controlled trial $\mathrm{BMC}$ Musculoskeletal Disorders (2007), 8:107.

18. Cynthia C. Norkin, D. Joyce White, Measurement of Joint Motion ; A Guide to Goniometry $3^{\text {rd }}$ Edition JayPee Brothers Medical Publishers (P) Ltd (2004) : Upper Extremity testing- The Shoulder, Pg. No. 78-81.

19. Farshid B. MD; Mohammed H. E. MD: Factors associated with pain, disability and quality of life in patients suffering from Frozen shouldrr. Arch bone joint surg (2016);4 (3) : 243-247.

20. Griggs SM, Ann A, Green A. Idiopathic adhesive capsulitis. A prospective functional outcome study of non-operative treatment 
21. Neviaser, RJ, and Neviaser, TJ: The frozen shoulder: diagnosis and management. Clin Orthop 223:59-64,(1987).

22. Pajareya K, Chadchavalpanichaya N, Painmanakit S, Kaidwan C, Puttaruksa $\mathrm{P}$ and Wongsaranuchit Y: Effectiveness of physical therapy with adhesive capsulitis: a randomised control trial, $\mathrm{J}$ Med Assoc Thai; 2004:87; 473-80.

23. Salameh Bweir Al Dajah: Soft Tissue Mobilization and PNF Improve range of motion and minimize pain level in shoulder impingement. J. Physio. Ther. Sci. 26:1803-1805 (2014).

24. Victoria Ryan, Hazel B., Catherine J. , and Jeremy S. Lewis : The pathophysiology associated with primary frozen shoulder : A systematic review, Ryan et al BMC Musculoskeletal Disorders (2016) 17:340.

25. Kristin M. MSC ; Amanda S. E , EdD; Craig Elder, $\mathrm{PhD}$; Andrea H., PhD: Myofascial release as a treatment for orthopaedic conditions : A Systematic review. Journal of Athletic Training (2013), 48 (4): 522-527. 